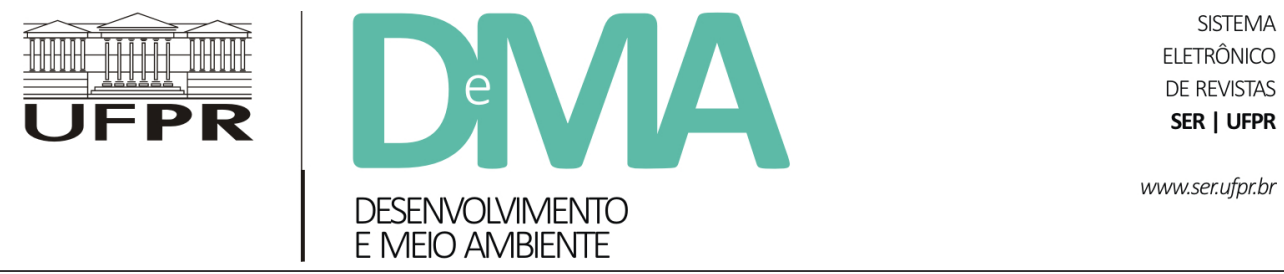

\title{
Políticas públicas e riscos ambientais em áreas de várzea na Amazônia: o caso do PRONAF para produção do açaí
}

\section{Public policies and environmental risks in floodplain areas in the Amazon: the case of PRONAF for açaí production}

\author{
Márcia de Pádua Bastos TAGORE¹, Otávio do $\mathrm{CANTO}^{1}$, Mário Vasconcellos SOBRINHO ${ }^{*}$ \\ ${ }^{1}$ Programa de Pós-graduação em Gestão dos Recursos Naturais e Desenvolvimento Local na Amazônia (PPGEDAM), Núcleo de Meio Ambiente \\ (NUMA), Universidade Federal do Pará (UFPA), Belém-PA, Brasil. \\ *E-mail de contato: mariovase@ufpa.br
}

Artigo recebido em 3 de abril de 2017, versão final aceita em 20 de março de 2018.

\begin{abstract}
RESUMO: $\quad$ Este artigo discute os riscos ambientais resultantes da implementação do Programa Nacional de Fortalecimento da Agricultura Familiar (PRONAF), com foco na produção de açaí (Euterpe oleracea) no estado do Pará. O açaí é uma importante espécie frutífera que serve como base alimentar da população das várzeas da região. Com o aumento de seu valor de mercado, maior produção e produtividade, houve uma alteração no sistema tradicional de manejo dos açaizais. A presente pesquisa buscou entender como esse novo manejo do açaí tem provocado mudanças no ambiente natural, ao mesmo tempo que procurou identificar os riscos ambientais decorrentes destas. Empiricamente, os dados foram levantados no município de Abaetetuba, no estado do Pará. Foram analisadas 56 Declarações de Aptidão ao PRONAF e coletados dados qualitativos em 10 propriedades por meio de entrevistas semiestruturadas, as quais foram realizadas entre maio e julho de 2016. A pesquisa mostra que o PRONAF tem sido um importante instrumento de apoio à produção rural e ao aumento da renda dos produtores de açaí. Entretanto, o Programa tem provocado alterações no ambiente natural, as quais resultaram nos seguintes riscos ambientais: (a) mudança na configuração da paisagem, com sua homogeneização e extinção de outras espécies; (b) erosão e assoreamento dos rios, resultante do aumento da área dos açaizais; (c) eliminação de espécies que protegem as margens das áreas de várzea; (d) dependência econômica dos ribeirinhos pela atividade do açaí e (e) perda da diversidade produtiva, uma característica essencial da agricultura familiar ribeirinha.
\end{abstract}

Palavras-chave: políticas públicas; Açaí; Várzea; Amazônia; riscos ambientais.

ABSTRACT: This paper discusses the environmental risks arising from the implementation of the National Programme for the Support of Family-based Farming (PRONAF) for açai production (Euterpe oleracea) in the state of Pará. Açaí is an important fruit species used as a food staple by people in the floodplain region. As its market value, 
production and productivity have increased, there have been significant changes in the traditional system of açaizais (açai plantations) management. The present study aimed to understand how açai management has caused changes in the natural environment and to identify the environmental risks arising from these changes. To this end, the research, conducted in the municipality of Abaetetuba, Pará, analyzed 56 Eligibility Declaration Documents to PRONAF and collected qualitative data from 10 properties using semi-structured interviews from May to July 2016. The results demonstrate that PRONAF has been an important tool to support rural production and to increase açai producers' income. However, açai management has caused changes in the natural environment which resulted in the following environmental risks: (a) change in landscape configuration, leading towards homogenization and extinction of other species; (b) river erosion and silting as an outcome of the increase of açaizais areas; (c) elimination of species that protect floodplain border areas; (d) riverine economic dependence on the açai activity; and (e) loss of productive diversity characteristic of riverine family-based farming.

Keywords: public policy; açaí floodplain; Amazonia; environmental risks.

\section{Introdução}

As políticas públicas de incentivo à produção rural na Amazônia, em especial uma política de crédito criada em 1995 chamada Programa Nacional de Fortalecimento da Agricultura Familiar (PRONAF) ${ }^{1}$, resultaram em intensa participação das organizações sociais, que buscaram o acesso a recursos financeiros para promover o desenvolvimento a partir da redução das desigualdades e inclusão socioeconômica da categoria familiar rural.

Ao longo dos anos, o Programa aplicou cerca de $\mathrm{R} \$ 160$ bilhões em mais de 26 milhões de contratos (Bianchini, 2015). De acordo com o mesmo autor, o Programa já oportunizou o acesso a quase um milhão de famílias por ano-safra, sendo inquestionável seu avanço enquanto programa de referência para o fortalecimento da agricultura familiar em todo o país e em especial na Amazônia. Com relação ao cultivo do açaí (Euterpe oleracea) de várzea no estado do Pará, o Programa tem sido a principal via de investimentos para o aumento dessa atividade (Oliveira, 2016).
O açaí é uma das fruteiras nativas mais importantes do estado do Pará, pois envolve um grande contingente de pessoas no processo produtivo e é responsável por cerca de $70 \%$ da renda dos ribeirinhos $^{2}$ (Lopes \& Santana, 2005). É uma espécie regional das matas de várzea que se destaca pelo seu valor econômico e alimentar, tanto para as populações ribeirinhas, quanto para as urbanas (Jardim, 1991; Nogueira \& Homma, 2014). De fato, trata-se de uma fruta que faz parte da base alimentar da maioria da população estuarina e que pode, também, ser aproveitada em sua totalidade para diferentes usos. Por exemplo, a raiz pode ser utilizada como produto medicinal, a estipe e as folhas podem ser utilizadas na construção rural e o palmito e os frutos servem como alimento (Calzavara, 1987; Cavalcante, 1991; Ohashi \& Kageyama, 2004). Também, o açaí pode ser usado na indústria de cosméticos (Balogh, 2011; Herculano, 2013) e confecção de biojóias (Benatti, 2013), dentre outros. A palmeira do açaí é encontrada de forma abundante no estuário da Amazônia (Jardim, 1987;

\footnotetext{
${ }^{1}$ Instituído através da Resolução do Conselho Monetário Nacional, no 2.191, de 24 de agosto de 1995 (Banco Central, 1995).

${ }^{2} \mathrm{O}$ termo ribeirinho é utilizado aqui como identidade das pessoas que vivem nas várzeas às margens dos rios e que, segundo Diegues (1999), tem como característica a prática do extrativismo.
} 
1991; Nogueira et al, 1998; Nogueira \& Homma, 2014), onde a concentração de açaizais manejados em áreas de várzea ocorre, principalmente, na desembocadura dos rios Tocantins, Pará e Amazonas (Homma, 2014). É uma palmeira típica de regiões de clima tropical (pluviosidade acima de $2.000 \mathrm{~mm}$, umidade relativa acima de $80 \%$ e temperatura média de $28^{\circ} \mathrm{C}$ ), mas pode se desenvolver em regiões com temperatura média acima de $18^{\circ} \mathrm{C}$ e em solos profundos de terra firme, desde que apresentem boa drenagem, e contenham elevado teor de matéria orgânica e umidade (Calzavara, 1987).

Em um estudo da Companhia Nacional de Abastecimento (Conab, 2015), o estado do Pará foi apontado como o maior produtor de açaí do Brasil. Com efeito, o Pará foi responsável pela produção de 111.073 toneladas do fruto no ano de 2013, correspondendo a $55 \%$ de toda a produção nacional, sendo que o estado é também seu maior consumidor. Em 2015 , foram exportados $4.983 .812 \mathrm{~kg}$ de polpa de açaí pelo valor de US\$22,523 milhões, o que corresponde a $84 \%$ do total de produtos de exportação do estado do Pará (Oliveira, 2016).

No ranking dos municípios do estado que comercializam o fruto in natura através dos portos de Belém, o município de Abaetetuba se encontra em $7^{\circ}$ lugar, com uma produção de 3.209,65 ton/ano (Oliveira, 2016). Esta produção alcançou tal magnitude em função do número de projetos e recursos obtidos para implementação do açaí manejado através do PRONAF. Entre 2003 e 2015 foram 7.828 contratos para a pequena agricultura familiar, o que equivale ao financiamento de $\mathrm{R} \$ 31.454 .864,56$ (Tagore, 2017). Como uma consequência, Abaetetuba passou a ser o município do estado do Pará com maior produção de açaí utilizando a técnica de manejo. Se, por um lado, Abaetetuba aumentou sua produção de açaí, esta produção, por outro lado, tem modificado o ecossistema de várzea, inclusive provocando significativas erosões nas ilhas que o compõem. Tais erosões ocorrem tanto pela produção em si do açaí manejado quanto pela abertura de canais para que pequenas embarcações adentrem nos furos, rios e igarapés, a fim de escoar a produção. Este conjunto de fatores e fenômenos identificados ao longo da pesquisa em Abaetetuba o fizeram ser escolhido como um caso peculiar para análise. Como aponta Ragin (1987), as pesquisas de caso não devem se voltar apenas à estrita compreensão das relações causais, mas também às características e condições que produzem os fenômenos estudados.

Em termos municipais, o cultivo do açaí e a pesca são as atividades mais importantes para a base econômica de Abaetetuba. A produção de açaí é voltada para o consumo na capital do estado e área metropolitana, bem como para a exportação para outros estados e países. O volume de recursos obtidos junto ao PRONAF coloca Abaetetuba em situação de destaque na produção do fruto.

Para Homma (2014), a crescente demanda pelo açaí e o aumento dos preços, principalmente na entressafra (janeiro a junho), têm levado à uma busca por alternativas para aumentar a produção e a produtividade, com emprego de novas técnicas e tecnologias, tanto nas áreas de produção tradicional de várzea como em áreas de terra firme.

Nos últimos 13 anos, a demanda pelo produto e o aumento de seu valor mercadológico resultou em uma nova conformidade no contexto de produção (Tagore, 2017). Se, por um lado, esse aumento no valor de mercado do açaí teve reflexos positivos na conservação dos açaizais nativos, por outro lado, tal aumento também motivou alterações no sistema produtivo. Este artigo mostra que as práticas de 
manejo dos açaizais nas áreas de várzea vêm sendo modificadas pelos ribeirinhos a fim de aumentar a produção e produtividade, e que essas novas práticas têm resultado em riscos ambientais como: (a) mudança na configuração da paisagem, com sua homogeneização e extinção de outras espécies; (b) erosão e assoreamento dos rios, resultante do aumento da área dos açaizais e, consequente, (c) eliminação de espécies que protegem as margens das áreas de várzea (Tagore, 2017). Estima-se que cerca de 80 mil hectares de várzea tenham se transformado em áreas homogêneas de açaí (Homma, 2014).

Para compreender as implicações do PRONAF na produção e demanda de açaí, bem como as consequente mudanças no sistema de produção em áreas de várzea e os riscos ambientais delas decorrentes, este artigo está estruturado em seis seções além desta introdução e das considerações finais.

Na seção 2, apresentamos as políticas públicas para o desenvolvimento rural sustentável no Brasil assim como seus reflexos no estado do Pará e no município de Abaetetuba. Apresentamos nessa seção o caso do PRONAF em especial e sua contribuição para o aumento da produção de açaí no estado e no município. Na seção 3, apresentamos o açaí, seu ambiente natural e sua importância para os produtores de várzea, chamados ribeirinhos. Ainda nessa seção, busca-se demonstrar alguns elementos constitutivos da mudança do extrativismo para o manejo intensivo. A seção 4 entra em uma discussão mais teórica a respeito do significado de risco ambiental, aqui entendido como um risco que envolve o meio ambiente físico, social e econômico. Para tal discussão, parte-se de um entendimento mais amplo de meio ambiente e, consequentemente, de risco ambiental. A seção 5 apresenta a área de pesquisa e a metodologia empregada no estudo. A seção 6 discute as principais alterações identificadas no ecossistema de várzea, aqui caracterizadas como riscos ambientais. É importante destacar que o presente artigo faz parte de uma pesquisa mais ampla, a qual discute o risco ambiental a partir de uma perspectiva expandida de meio ambiente que ultrapassa a visão centrada nos recursos naturais.

\section{Políticas públicas para o desenvolvimento rural sustentável e seus reflexos no Pará e no município de Abaetetuba}

Em 1996, o INCRA (Instituto Nacional de Colonização e Reforma Agrária) criou, com foco na região amazônica, uma modalidade de assentamento denominada Projeto de Assentamento Agroextrativista (PAE). Tal modalidade teve como objetivo regularizar as terras para populações extrativistas que já se encontravam nas áreas da União. Essas áreas, de domínio público e de responsabilidade do INCRA, foram repassadas às populações tradicionais através de concessão de direito real de uso e passaram a ser administradas pelas normas organizativas dessas populações (Incra, 2016).

Por meio do PAE, as famílias podem realizar, dentre outras atividades, a coleta de frutas, sementes, resinas, óleos e plantas medicinais, desde que o façam através do manejo sustentável da floresta e da agricultura. Ou seja, é permitida a extração de recursos naturais por meio de atividades economicamente viáveis que sejam, ao mesmo tempo, ecologicamente sustentáveis (Incra, 2016).

Em 2005, a Secretária do Patrimônio da União (SPU) disciplinou o uso e aproveitamento dos recursos naturais das várzeas através de uma autorização de uso para o desbaste de açaizais, colheita de frutos 
ou manejo de outras espécies extrativistas, conforme o artigo $1^{\circ}$ da portaria (Secretaria do Patrimônio da União, 2005). Isso se deu, entre outros fatores, devido a morosidade na efetivação dos PAEs no âmbito da Amazônia.

Entre os anos de 2003 e 2015, no município de Abaetetuba, de tradição extrativista, foram criados 24 PAEs que receberam grande volume de financiamento para produção de açaí, visto que estes projetos se enquadram como beneficiários ${ }^{3}$ do PRONAF por intermédio do Banco da Amazônia S. A. (BASA) (Figura 1).
A EMATER-PARÁ, através da equipe do escritório de Abaetetuba, elaborou 753 projetos em 2014 , pelo valor médio de $\mathrm{R} \$ 7.365,72$ por projeto, totalizando R\$5.546.386,06. Em 2015, embora a quantidade de projetos elaborados tenha sido inferior, a média do valor financiado correspondente foi superior aos anos anteriores, o que demonstra o crescente investimento na região voltado a projetos de cultivo de açaí.

Cabe ressaltar que a maioria dos projetos se realizou por meio da linha de financiamento PRONAF A, a qual contempla beneficiários do

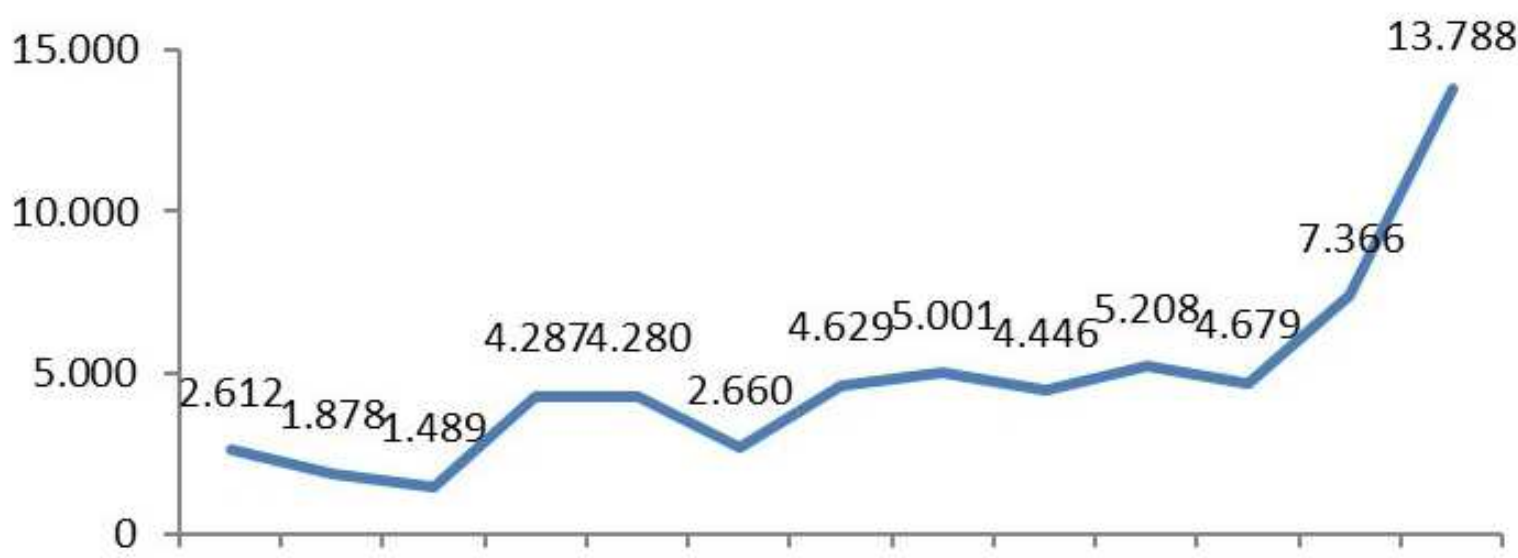

2003200420052006200720082009201020112012201320142015

Média do valor contratado por numero de contrato

FIGURA 1 - Projetos para cultivo de açaí financiados pelo BASA em Abaetetuba, entre os anos de 2003 a 2015. FONTE: Tagore (2017).

\footnotetext{
${ }^{3}$ Conforme a lei $\mathrm{n}^{\mathrm{o}} 11.326$, de 24 de julho de 2006, são beneficiários do programa agricultores que: não detém área maior do que 4 (quatro) módulos fiscais, utilizam mão-de-obra da própria família, tenham percentual mínimo da renda familiar originada de atividades econômicas do seu estabelecimento, e que dirijam seu estabelecimento com sua família. Esta lei se aplica também aos silvicultores, aquicultores, extrativistas, pescadores, povos indígenas, remanescentes de quilombos rurais, e demais povos e comunidades tradicionais, além de assentados de reforma agrária.
} 
Programa Nacional de Reforma Agrária (PNRA) enquadrados nos grupos A e AC da Declaração de Aptidão (DAP) ${ }^{4}$ ao PRONAF. Os projetos possuem um limite no valor de $\mathrm{R} \$ 25.000,00$, conforme Manual de Crédito Rural (MCR)-17.

Das 72 ilhas de Abaetetuba, 24 são PAE e, destas, nove tiveram projetos de cultivo de açaí financiados no ano de 2015. Ao longo dos últimos anos, estas nove também receberam investimentos via PRONAF A (Projetos de Estruturação Complementar), que compreende recursos financeiros voltados a implantação, ampliação, recuperação ou modernização de infraestruturas produtivas, que podem ou não estar relacionadas com projetos de produção. Todavia, estes devem estar em consonância com o que determina o Plano de Recuperação de Assentamentos (PRA).

Por meio do PRONAF Floresta, foram viabilizados 25 projetos para os ribeirinhos que não estão na Relação de Beneficiários (RB) do INCRA, contabilizando R $\$ 401.574,00$ no total. Estes ribeirinhos não se enquadram na categoria de assentados, motivo pelo qual não podem acessar recursos por meio da linha de financiamento PRONAF A.

O PRONAF Floresta atende todos os agricultores familiares beneficiários do programa através da implantação de projetos de sistemas agroflores- tais (SAF), exploração extrativista ecologicamente sustentável, plano de manejo, e manejo florestal, com financiamento de: até $\mathrm{R} \$ 15$ mil para SAF de agricultores familiares que se enquadrem na DAP $\mathrm{A}, \mathrm{B}$ e A/C; R $\$ 35$ mil para SAF de agricultores familiares com DAP V; e R $\$ 25$ mil para os demais, segundo MCR-7.

Outra linha de crédito que tem sido utilizada é o Fundo Constitucional de Financiamento do Norte $(\mathrm{FNO})^{5}$ - Biodiversidade, nas seguintes categorias: (1) Reserva legal - Área de Preservação Permanente (APP) ${ }^{6}$, destinada a empreendimentos voltados à regularização e recuperação de áreas de reserva legal e áreas de preservação permanente nas propriedades rurais, as quais foram degradadas/ alteradas; e (2) Uso alternativo do solo, que destina recursos, especificamente, para a manutenção e recuperação da biodiversidade da Amazônia, a partir da concessão de financiamentos à empreendimentos que privilegiam o uso racional dos recursos naturais, com adoção de boas práticas de manejo, e que são acessadas por populações tradicionais da Amazônia?.

Em função da importância econômica da cadeia do açaí, que mobiliza mais de 300 mil pessoas em 54 municípios, representando cerca de $70 \%$ da renda da população ribeirinha (Oliveira, 2016), o

\footnotetext{
${ }^{4} \mathrm{~A}$ DAP é o instrumento utilizado para identificar e qualificar as unidades produtivas da agricultura familiar e suas formas associativas organizadas em pessoas jurídicas. A DAP foi criada pelo Conselho Monetário Nacional (CMN) e é emitida por instituições credenciadas junto à Secretaria Especial de Agricultura Familiar e do Desenvolvimento Agrário (SEAD), vinculada à Casa Civil da Presidência da República.

${ }^{5}$ Os Fundos Constitucionais foram criados pela Constituição Federal de 1988, a qual estabelece, em seu artigo 159, inciso I, alínea "c", que $3 \%$ da arrecadação do IR (Imposto sobre a Renda) e IPI (Imposto sobre Produtos Industrializados) devem ser aplicados em programas de financiamento destinados aos setores produtivos das Regiões Norte, Nordeste e Centro-Oeste, regulamentado pela Lei ${ }^{\circ} 7.827$, de 27.09 .89$.

${ }^{5}$ Art. $3^{\circ}$ da Lei 12.651 de 25. 05.2012: dispõe sobre a proteção da vegetação nativa.

${ }^{7}$ O Decreto $n^{\circ}$ 6.040, de 7.02.2007, institui a Política Nacional de Desenvolvimento dos Povos e Comunidades Tradicionais (PNPCT), a qual considera os grupos culturalmente diferenciados que possuem formas próprias de organização social, que ocupam e usam territórios e recursos naturais como condição para sua reprodução e conhecimentos, inovações e práticas gerados e transmitidos pela tradição, compreendendo os povos indígenas, comunidades quilombolas, ribeirinhos, extrativistas, pescadores artesanais, entre outros povos da floresta.
} 
estado do Pará criou, em 2011, o Programa Estadual de Qualidade do Açaí (PEQA) ${ }^{8}$. Este é coordenado pela Secretaria de Estado de Agricultura (SAGRI), atual SEDAP, e envolve 14 instituições públicas e privadas com o objetivo de introduzir boas práticas em toda a extensão da cadeia produtiva do açaí (produção agrícola, transporte, comercialização, e fabricação artesanal e industrial), de modo a garantir um padrão de qualidade para o produto.

Em 2007, a alta incidência da doença de chagas no Pará foi atribuída à ingestão de açaí contaminado com o protozoário causador da doença, pois o surgimento deste protozoário estava relacionado com a falta de higiene e manuseio inadequado do produto. Portanto, os estabelecimentos comerciais e o governo do estado do Pará foram obrigados a assumir um Termo de Ajustamento de Conduta (TAC) junto ao Ministério Público do Estado (MPE), de forma a se adequarem às normas de higiene previstas pela Lei 8.918/94, a qual dispõe sobre o padrão de produção de bebidas derivadas de frutos.

A CONAB (2015) estabeleceu normas específicas, para associações e cooperativas, para a safra 2016/2017 de açaí proveniente de atividade extrativista, e concedeu R $\$ 1.000,00 /$ safra por DAP como financiamento para estocagem do produto. $\mathrm{O}$ objetivo é garantir o preço mínimo básico fixado pela Portaria n. ${ }^{\circ} 123$ do Ministério da Agricultura, Pecuária e Abastecimento (MAPA), de 05/07/2016, correspondente ao valor de $\mathrm{R} \$ 1,29 / \mathrm{kg}$ do fruto. Além disso, o Programa Nacional de Alimenta- ção Escolar (PNAE) ${ }^{9}$, do Ministério da Educação (MEC), incentiva a aquisição do açaí para a merenda escolar, consequentemente estimulando seu status como produto de referência.

As instituições de pesquisa e de Assistência Técnica e Extensão Rural (ATER), por sua vez, vêm estimulando o manejo do açaí em áreas de várzeas do estuário amazônico. Tal estímulo consiste da utilização de técnicas e práticas para melhor o rendimento dos sistemas de exploração do produto (Nogueira, 1997).

No âmbito da ATER pública, efetivada pela Empresa de Assistência Técnica e Extensão Rural (EMATER-PARÁ), orientada pela Política Nacional de Assistência Técnica e Extensão Rural (PNATER), e regida por princípios agroecológicos, há a preocupação de estimular práticas sob essa orientação produtiva. Dessa forma, estimula-se capacitações no âmbito da instituição, tanto para técnicos quanto para produtores ribeirinhos, para a difusão e implementação dessas práticas que ainda são incipientes na região.

Como não há uma definição clara sobre o que é permissível na atividade de manejo do açaí, é necessário esclarecer que o manejo aqui referido compreende todas as atividades praticadas em relação ao fruto: limpeza da área (eliminação de outras espécies, independente do porte), tratos culturais (desbaste, poda de galhos e perfilhos, controle de plantas invasoras consideradas daninhas e indução da inflorescência), controle de pragas e doenças,

\footnotetext{
${ }^{8}$ Decreto Estadual n ${ }^{\circ} 2.475 / 2010$

${ }^{9}$ O PNAE é derivado do Programa de Alimentação Escolar criado na década de 50 que, em 2009, através da Lei ${ }^{\circ} 11.947$, garante que, no mínimo, 30\% dos repasses do Fundo Nacional de Desenvolvimento da Educação (FNDE) sejam investidos na aquisição de produtos da agricultura familiar. Em 1994, a Lei n ${ }^{\circ} 8.913$, de 12/7/94, concede a celebração de convênios entre a União e os municípios, obrigando que 70\% dos recursos transferidos pelo governo federal sejam aplicados em produtos básicos, respeitando os hábitos alimentares regionais.
} 
preparo de mudas, transplantio, plantio, colheita, debulha, limpeza, e acondicionamento do fruto. Quando tratamos de manejo intensivo, referimo-nos a quaisquer dessas ações que sejam praticadas de forma impetuosa, sem considerar as consequências futuras.

Entre a pesquisa, a orientação técnica, e a implementação prática pelos agricultores, existe um longo caminho a ser percorrido por eles referente à informação técnico-científica recebida. A informação, ao longo do percurso, se fragmenta e resulta em diferentes interpretações e possíveis distorções, as quais acabam provocando alterações no processo de produção, algumas mais perceptíveis que outras e que, em áreas de várzea, incorrem, inclusive, em questões de ordem legal.

\section{Várzea, açaí e os ribeirinhos: do extrativismo ao manejo intensivo}

As várzeas ${ }^{10}$ são grandes faixas que margeiam os rios e que, periodicamente, são cobertas por águas, constituindo-se em reservas potenciais de nutrientes em função da fertilidade que apresentam (Canto, 2007). São áreas protegidas por lei e consideradas como inundações, ou planície de inundações, adjacentes a cursos de água que permitem o escoamento de enchentes (Brasil, 2012).

As várzeas são classificadas como áreas úmidas sujeitas a uma fase aquática e outra terrestre, cuja va- riação se dá em função do pulso de inundação (Junk et al., 1989). São periodicamente inundadas por rios de água branca e representam o principal tipo de vegetação da Amazônia (Pires \& Prance, 1985). Devido ao aporte de sedimentação de matéria orgânica, as várzeas são ricas em nutrientes (Sioli, 1985).

Segundo Junk (1997), as várzeas são habitat natural de uma grande quantidade de espécies. Para o autor, os processos físicos e biológicos são essenciais para a manutenção da biodiversidade, sendo as várzeas da Amazônia ambientes frágeis que quando alterados pela ação humana são difíceis de serem recuperadas.

O açaizeiro é uma das espécies mais importantes da região do estuário da Amazônia (Silva \& Almeida, 2004). Segundo Mourão (2010), há registros do uso secular do açaí pelos indígenas ${ }^{11}$ como fonte de alimento. À época, a produção era oriunda da atividade extrativista e o beneficiamento se realizava no local da colheita, de forma artesanal. O consumo, por sua vez, era eminentemente familiar, forma que perdurou por um longo período.

Com o processo de urbanização nos anos de 1960 e 1970, o consumo do açaí se estendeu para as periferias das cidades e passou a ter lugar importante, também, na dieta das famílias das áreas urbanas. Neste período houve também a ocorrência de derrubada de grandes áreas de açaizais nativos para extração de palmito (Homma, 2014), devido a diminuição do estoque da palmeira juçara (Euterpe edulis) na Mata Atlântica (Nogueira, 1997; Nogueira \& Homma, 2014).

\footnotetext{
${ }^{10}$ A Lei 12.651 (Brasil, 2012), no Art. 4 ${ }^{\circ}$, inciso I, ao tratar da tipificação de Área de Preservação Permanente (APP), não especifica claramente o termo várzea, ficando subentendida a contemplação dessas áreas como faixas marginais de cursos de água. Esta situação, por não incluir as demais áreas alagadas, fragiliza a proteção desse ecossistema, gerando dúvidas quanto ao seu enquadramento na lei. O termo várzea só fica evidenciado para efeito de proteção enquanto APP quando declaradas de interesse social por ato do poder executivo, conforme o Art. $6^{\circ}$, inciso III da mesma lei.

${ }^{11}$ Segundo Mourão (2010), açaí é um termo de origem tupi que significa "palmeira de água”, e as tribos indígenas da região do estuário amazônico eram denominadas de I'DE-NASÃ, que significa "povo da água", e suas malocas eram chamadas de MIXI-THA, ou seja, "açaizal”, o que pressupõem uma grande quantidade de açaí na área.
} 
Nos anos de 1980, a diminuição das palmeiras no sudeste do país, fruto da extração predatória, fez com que o palmito do açaí ganhasse relevância em termos comerciais. No período, o Pará se tornou a principal unidade da federação na extração e produção de palmito em conserva, sendo responsável por 95\% da produção nacional (Mourão, 2010).

Nos anos de 1990, segundo Nogueira \& Homma (2014), o palmito se destacou entre os produtos de exportação do Pará, atrás apenas dos produtos madeireiros, dendê (Elaeis guineensis) e pimenta do reino (Piper nigrum). Sua produção chegou a atingir, em 1996, 14,2 milhões de dólares, porém, o estoque de plantas para produção do suco ou polpa diminuiu. Além disso, ainda nessa década, o suco de açaí toma conta das academias de ginásticas e faz sucesso como energético natural. Esta procura pelo produto em mais esse setor do mercado eleva o status do açaí como produto, também, das classes de maior poder aquisitivo (Santana et al., 2006).

Tal valorização do fruto, constatada ainda na década de 1990, resultou na conservação dos açai- zais, que deixaram de ser derrubados para a extração de palmito e passaram a ser mantidos na área para produção de frutos, conforme registros de Homma (1989) e Nogueira (1997). Essa tendência se confirma e se amplia a partir da década de 2000, consolidando o açaí como um importante produto de mercado, uma vez que passa a ter grande procura em nível nacional e internacional.

O crescimento da demanda do açaí despertou grande interesse no manejo das áreas de várzea (Homma, 2014). Os dados levantados junto à CONAB (2015) demonstram um crescimento exponencial de mais de 500\%, com variações no período de 2000 a 2014, quando o menor preço médio pago por lata de $13 \mathrm{~kg}$ foi de $\mathrm{R} \$ 7,5$ e o maior foi de $\mathrm{R} \$ 39,15$. A variação da inflação no mesmo período, medido pelo Índice Geral de Preços do Mercado (IGP-M), foi de 213,43\%. Isto significa que o valor R $\$ 7,5$ em 2000 corresponderia a $\mathrm{R} \$ 16,00$ em 2014, valor muito inferior aos $\mathrm{R} \$ 39,15$ praticados em 2014. Este comportamento significa um aumento no valor praticado, que foi $245 \%$ maior do que a inflação (Figura 2).

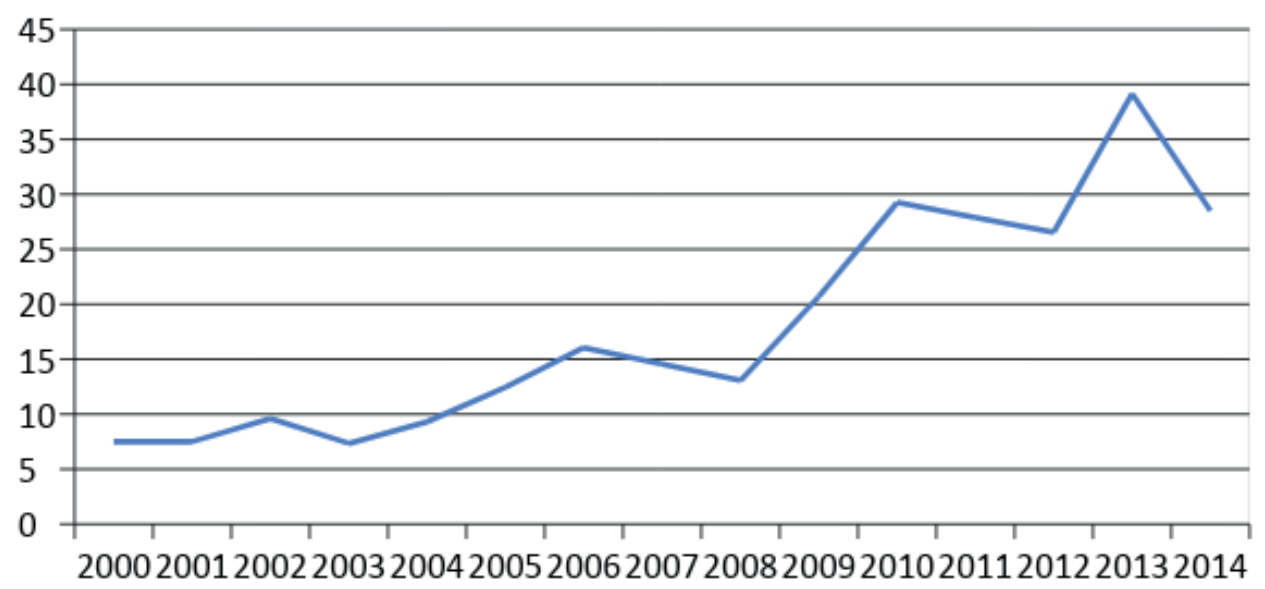

FIGURA 2 - Preço médio anual da lata $(13 \mathrm{~kg})$ de açaí em fruto no Pará no período 2002 a 2014. FONTE: Tagore (2017). 
Paralelamente ao crescimento do açaí, vários fatores positivos e negativos foram surgindo, derivados do processo de produção. Dentre estes, como já citado, está o consumo do açaí contaminado. Segundo Passos et al. (2012), o consumo de alimentos contaminados está associado à veiculação do protozoário Trypanosoma cruzi, que é transmitido para os seres humanos e animais por via das fezes do inseto hematófago popularmente conhecido como "barbeiro" que, algumas vezes, é encontrado na polpa de açaí1 ${ }^{12}$ e que causa a doença tropical parasitária conhecida como doença de Chagas. Segundo o mesmo autor, a maior incidência do vetor está relacionada com a homogeneização da paisagem e o crescimento de aglomerados humanos no ambiente da produção do açaí. Ao aumentar a quantidade de plantas de açaí na área, eliminando espécies que abrigam predadores do inseto, há o desequilíbrio do meio natural e o aumento do risco de crescimento da população desse vetor.

O manejo tradicional dos açaizeiros adotado na região compreendia o desbaste e corte das estirpes mais altas e mais velhas, além da coleta dos frutos com o auxílio da "peconha"13 Todavia, atualmente, as práticas seguidas nos açaizais compreendem diferentes atividades que, em geral, são mais agressivas.

Quando as práticas de manejo são utilizadas de forma intensiva e agressiva para o predomínio dos açaizeiros, as mesmas colocam em risco o ambiente natural onde os açaizeiros se encontram, pois eliminam outras espécies, provocam erosão e assoreamento dos rios e, consequentemente, alteram fortemente a paisagem local.

\section{Os riscos ambientais}

Segundo Beck (2010), os riscos são consequências técnico-científicas de um determinado estágio de produção, os quais precisam ser compreendidos no espaço que ocorrem, pois estão associados a escolhas políticas e/ou econômicas. Neste sentido, a relação entre as políticas públicas de incentivo à produção e os riscos ambientais delas derivadas se apresentam autoevidentes.

Para o autor, a sociedade moderna tenta demonstrar que possui domínio sobre os riscos das ações que são baseadas no atual modelo de desenvolvimento das sociedades industriais. Contudo, as permanentes catástrofes ambientais, como a recente tragédia ocorrida no município de Mariana, Minas Gerais, já demonstraram que a ciência e a técnica não têm dado conta da predição e controle dos riscos ecológicos, químicos, nucleares, genéticos, dentre outros. Há a necessidade, por parte das instituições e dos agentes, de se criar certezas que resultam em garantias para esse modelo de desenvolvimento através de previsão de soluções, embora seja difícil em face do futuro imprevisível (Beck, 2010). A invisibilidade imediata dos riscos da modernização coloca os cientistas numa posição-chave como intérpretes do perigo e, por meio deles, os riscos

\footnotetext{
${ }^{12} \mathrm{Em}$ 2006, foram registrados 430 casos da doença (Passos et al., 2012).

${ }^{13}$ Peconha é o traçado de corda, tecido ou fibra que serve de apoio para os pés na escalada de árvores, com o qual o coletor, ao pressionar as pernas junto ao caule das árvores e impulsionar o corpo para cima, consegue subir nas mesmas. A atividade demanda grande esforço físico, pois é utilizado principalmente as pernas e braços. No caso do açaizeiro, este é um método tradicional amplamente utilizado na região para coleta dos cachos de frutos (Tagore, 2017).
} 
podem sofrer minimização ou dramatização (Beck, 2010). Segundo Leite \& Ayala (2004), a sociedade está exposta a um elevado grau de indeterminação de riscos, o que demonstra a incapacidade funcional dos padrões normativos de regulação jurídica do ambiente, fundamentados em processos de gestão racional e científica. Na sociedade de risco, a intenção que precede a ação se orienta por um cálculo prévio dos efeitos desejados versus os efeitos não desejados previstos. Entretanto, há uma tendência a desconsiderar, ou tender racionalmente a desconsiderar a possibilidade da existência de efeitos imprevisíveis que podem anular os benefícios pretendidos. Em outras palavras, os sucessos da modernização têm gerado efeitos colaterais imprevisíveis, efeitos estes que tendem a escapar dos mecanismos de controle institucional da sociedade (Beck, 2010).

As instituições buscam fazer com que os efeitos inicialmente não imaginados sejam passiveis de ser previsíveis, mediante o aperfeiçoamento técnico. Entretanto, por tal via, isto significa mais tecnologia, mais crescimento, mais produtividade e, consequentemente, a geração de mais riscos.

Segundo Beck (2010), a noção de sociedade de risco indica que os riscos são democráticos, pois afetam nações e classes sociais sem respeitar fronteiras de nenhum tipo. A globalização dos riscos, entretanto, não significa igualdade global frente a eles. Isto porque, segundo o que define a primeira lei dos riscos ambientais, os maiores problemas do modelo de desenvolvimento atingem os mais pobres, ou seja, as populações mais carentes que, por terem menos recursos, tendem a ser as mais afetadas.

Os efeitos produzidos pela sociedade moderna são evidentes e apresentam, simultaneamente, oportunidades e perigos. Essa ambiguidade do risco impera na necessidade de se decidir entre aproveitar as oportunidades ou perde-las. O risco é, também, uma grandeza de experimentação, fazendo parte, portanto, da dimensão da ordem das probabilidades, com um alto grau de incertezas que, atualmente, não pode ser resolvido através do conhecimento (Beck 2010).

A atividade agrícola moderna é regulada por forças mercadológicas e sistemas de plantations, e como o meio natural é extremamente susceptível a imprevistos, os riscos ambientais e sociais aumentam (Monteiro, 2017). No sistema extrativista tradicional de produção, entretanto, não há adoção de processo de cultivo. A produção ocorre naturalmente e respeita a heterogeneidade local. O produto, em geral, é destinado para a manutenção das famílias e, portanto, adequa-se como uma atividade sustentável e com riscos menores (Tagore, 2017).

Todavia, o cenário atual do extrativismo do açaí apresenta tentativas de superar as limitações de produção e produtividade que o sistema natural propõe. Busca-se a oferta do produto em maior espaço de tempo em função da sazonalidade da safra. Dessa forma, outros tipos de produção têm sido experimentados e fomentados, principalmente a partir de mudanças nas formas de manejo, o que tem gerado grandes alterações no processo de extrativismo e beneficiamento do açaí.

Existem diferentes formas de manejo, que vão desde uma atividade de desbaste até a eliminação total das plantas do entorno. Portanto, as propostas para o aumento da produtividade do açaí merecem mais investigação, conforme destacado por Homma (2014).

A homogeneização da paisagem se dá pela prevalência de uma espécie em detrimento de outras. Resulta na eliminação de espécies que tem papéis 
inerentes no habitat. Consequentemente, há uma série de problemas ocasionados pelo desequilíbrio do meio natural.

Os ribeirinhos identificam e reportam às instituições governamentais problemas de ordem ambiental, como o assoreamento dos rios, o acúmulo de lixo, e até mesmo a mudança no horário de navegação em função da alteração das marés. Essas questões podem, aparentemente, não ter relação com os riscos ambientais. Entretanto, os riscos são decorrentes da forma como o ambiente natural tem sido impactado pelo homem.

As soluções encontradas em nível de comunidade perpassam esforços em âmbitos diferenciados que, ao trabalharem de forma conjunta e parceira, devem buscar resolver os entraves comunitários por via da adequação das políticas públicas à realidade local. Ao considerar as ações de parceria, segundo Vasconcellos Sobrinho \& Vasconcellos (2016), é necessário que seja estabelecido, entre indivíduos e organizações, a confiança e sinergia para que os conflitos e riscos sejam contornados e os diferentes interesses dos agentes envolvidos sejam reconhecidos. Dessa forma, todos podem participar da tomada de decisão, em especial os desemponderados que, no caso, são os produtores ribeirinhos.

\section{5. Área de pesquisa e metodologia}

O município de Abaetetuba (Figura 3) faz parte da Região de Integração do Tocantins, com população estimada de 150.431 habitantes. $42 \%$ desses habitantes residem na área rural, distribuídos em uma área territorial de $1.610,408 \mathrm{~km}^{2}$ recortada por rios e furos, com 72 ilhas (Mapa 1). Esta composição geográfica o caracteriza como o município do Pará com o maior número de ilhas espalhadas ao longo de seu recorte político-administrativo, e também aquele que possui a maior extensão de áreas de várzea no estado com produção de açaí manejado. Conforme referido anteriormente na introdução deste artigo, em função da forte presença do manejo de açaí, há em Abaetetuba escavações de canais para facilitar o transporte do produto em embarcações de pequeno porte, o que tem causado erosão e mudanças no ecossistema de várzea.

O município conta com a Cooperativa de Fruticultores de Abaetetuba (COFRUTA), que possui cerca de 120 cooperados e dispõe de infraestrutura para auxiliar na comercialização do açaí, seu principal produto de trabalho.

A população residente das ilhas de Abaetetuba recebeu, nos últimos 13 anos, investimentos públicos através de dois dos principais programas do governo federal voltados à agricultura familiar: O PAE, na área de assentamentos rurais; e o PRONAF, na área de financiamento creditícios para a produção agrícola. Como já explicitado em outras seções deste artigo, o município de Abaetetuba possui 24 Projetos de Assentamentos Extrativistas (Figura 4), localizados, em sua maioria, em áreas de várzea, o que determina as condições naturais para produção de açaí.

Metodologicamente, as informações necessárias a respeito dos sistemas de produção e dos riscos ambientais nas áreas de várzea do município de Abaetetuba foram obtidas por meio de quatro procedimentos: pesquisa documental, análise visual, observação direta, e entrevistas semiestruturadas. Na pesquisa documental foram examinadas 56 DAP ao PRONAF, os relatórios de aplicação dos programas de financiamento dos agentes creditícios, e os projetos de financiamento para o cultivo de açaí. 
A análise visual ocorreu através da apreciação da paisagem de 10 propriedades, buscando apreender as alterações ambientais como assoreamento dos rios, queda de barrancos das áreas ribeirinhas, e homogeneização das espécies. Na observação direta foram consideradas as dinâmicas de produção do açaí e as diversas formas de manejo realizadas pelos produtores. As entrevistas foram realizadas com 10 produtores e ocorreram entre maio e julho de 2016. $\mathrm{Na}$ sede do município, foram entrevistados cinco técnicos da ATER, um representante da Prefeitura, e dois gestores da cooperativa COFRUTA.

As Declarações de Aptidão e os produtores ribeirinhos foram escolhidos de forma aleatória dentre aqueles que receberam financiamento via PRONAF entre 2003 a 2016. O trabalho de campo foi realizado junto à equipe da EMATER-PARÁ do escritório de Abaetetuba, por ocasião de vistoria obrigatória para emissão de laudo a ser enviado ao agente financeiro, para a liberação de parcelas do financiamento.

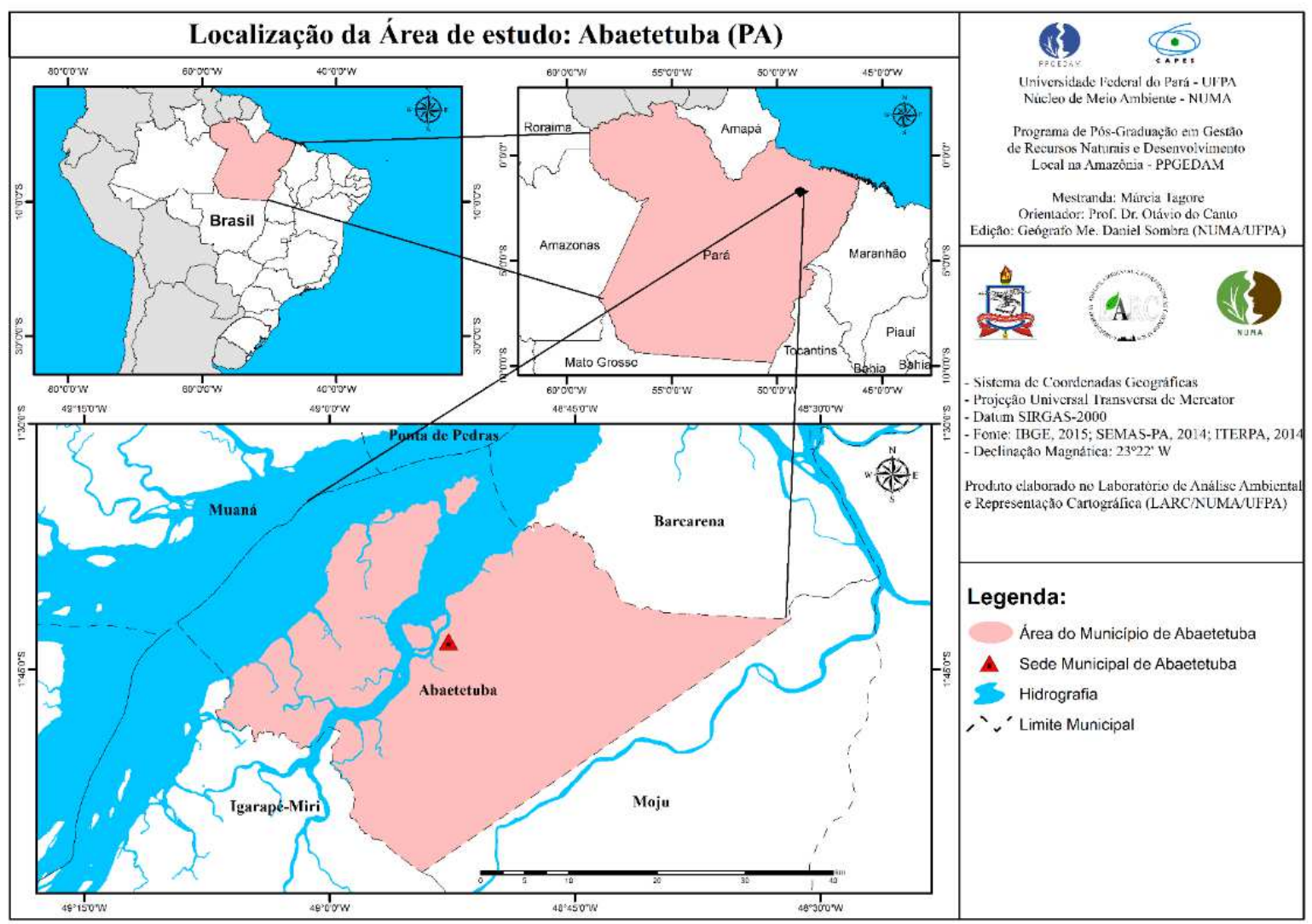

FIGURA 3 - Município de Abaetetuba, Pará. FONTE: Tagore (2017). 


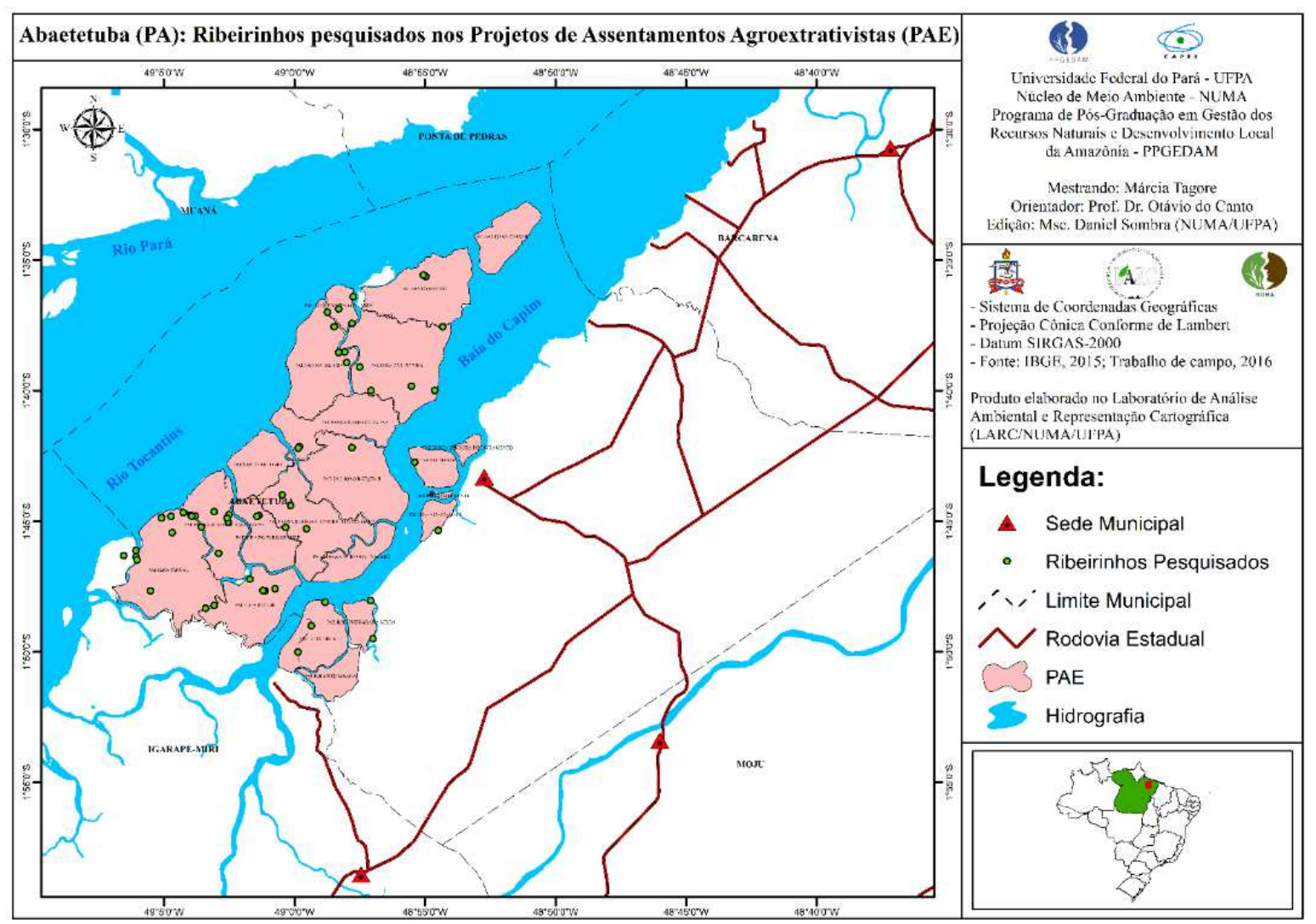

FIGURA 4 - Imagem dos 24 PAEs do município de Abaetetuba, Pará e os pontos das propriedades dos 56 ribeirinhos pesquisados. FONTE: Elaboração dos autores com base nos dados do Ibge (2014) e Incra (2016).

\section{Sistemas de produção de açaí e riscos ambientais identificados no ecossistema de várzea}

O atual sistema de produção extrativa do açaí na várzea utiliza novas práticas de manejo, buscando superar as limitações de produção e produtividade. Estas práticas incluem o desbaste das brotações e o corte das árvores do entorno das touceiras dos açaizais. Isto é feito para potencializar a luminosidade, dar maior poder de competitividade contra outras espécies para a palmeira de açaí, e permitir os transplantios de brotações de touceiras e plantios de mudas de açaí dentro das áreas de ocorrência espontânea. Como resultado, há a conformação de áreas homogêneas de açaí, corroborando os registros de Homma (2014), os quais indicam que as novas práticas de manejo de açaizais tem implicado na remoção da cobertura vegetal original, por meio da retirada das espécies que competem com os açaizeiros.

Consequentemente, o sistema produtivo do açaí vem se configurando como produção de 
monocultura em áreas de várzea e já se constata problemas que derivam desta opção de cultivo. As alterações são visíveis e facilmente detectadas, inclusive por meio de observações simples, conforme demonstrado na Figura 5. Nesta, pode-se observar a predominância quase que exclusiva de açaizeiros. $\mathrm{O}$

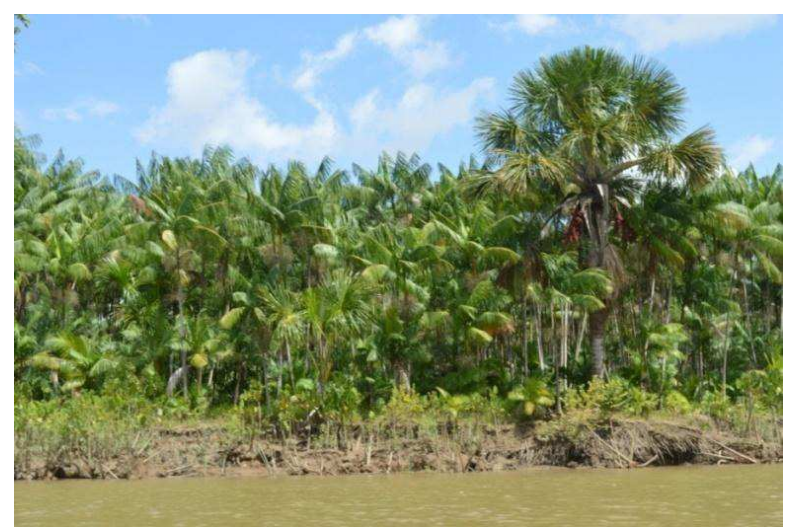

FIGURA 5 - Plantio de açaí em área de várzea em Abaetetuba (PA). FONTE: Pesquisa de campo.

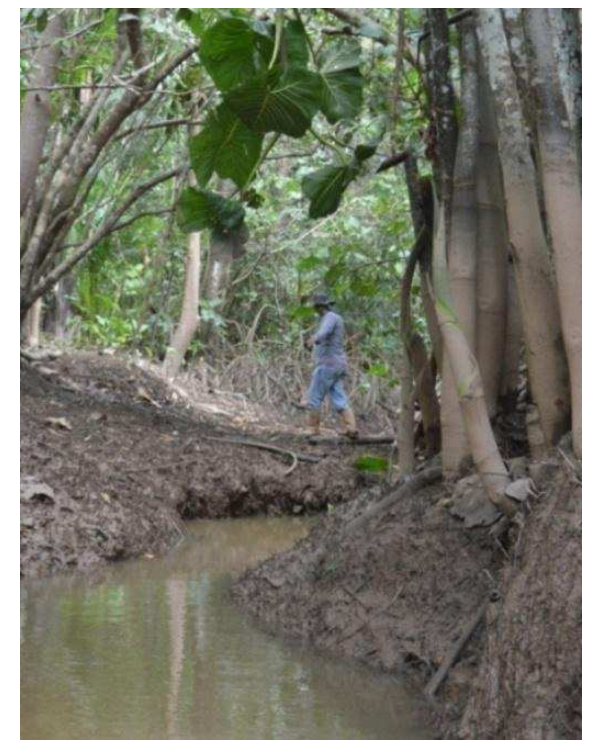

FIGURA 6 - Canal construído para passagem de pequenas embarcações.

FONTE: Pesquisa de campo. miritizeiro ainda é preservado devido a sua importância para a economia local de Abaetetuba, sendo utilizado para um artesanato específico e característico do município. Entretanto, esta é uma exceção.

Além da homogeneização da paisagem, pôde-se constatar, nas observações de campo, a ocorrência de canais nas proximidades das áreas de produção (Figura 6), que foram abertos para facilitar a drenagem da água inundada pelas marés e permitir o acesso dos barcos para o transporte de frutos. Estes canais provocam erosão das margens dos rios e igarapés, e impactam o meio físico do ambiente (Homma, 2014).

É fato que o processo de degradação do meio físico natural, com depredação de espécies lenhosas da região Tocantina paraense, se inicia de forma intensiva ainda no século XVI. Portanto, tem-se um século e meio de exploração vegetal que culmina com a escassez de algumas espécies de árvores utilizadas na alimentação dos ribeirinhos da região. No século XVIII, a dinâmica de ocupação comprometeu a regeneração natural, e o governo português teve que adotar diferentes estratégias, como a transferência de área, e utilizar novas formas de exploração, passando de sistema extrativista para sistema agroextrativista (Menezes \& Guerra, 1998).

Os estoques florestais madeireiros das áreas de várzea do estuário da região foram os primeiros a serem explorados. O processo de extração madeireira se intensificou com a instalação de grandes empresas a partir de meados do Século XX, levando ao desaparecimento do estoque de várias espécies (Castro et al., 2010).

Na perspectiva dos entrevistados, os indivíduos remanescentes de espécies como Ucuuba/Virola (Virola surinamensis), Cedro (Cedrellafissilis) e Andiroba (Carapaguianensis) diminuíram significativamente 
nos últimos 15 anos. Além destas, os entrevistados assinalam outras 12 espécies que diminuíram substancialmente (Tabela 1).

TABELA 1 - Espécies que tiveram redução de indivíduos nos últimos 13 anos, indicadas na pesquisa.

\begin{tabular}{|c|c|c|}
\hline Nome Vulgar & Nome Científico & Percentual (\%) \\
\hline Cedro & Cedrellafissilis & 13 \\
\hline Andiroba & Carapaguianensis & 13 \\
\hline Sucupira da várzea & Diplotropismartiusii & 7 \\
\hline Palheira & Manicariasaccifera & 7 \\
\hline Mangueiro & Rhizophoramangle & 7 \\
\hline Aturiá & Machaeriumferox/Drepanocarpuslunatus & 7 \\
\hline Aninga & Philodendronspeciosum & 7 \\
\hline Paxiúba & Socrateaexorrhiza & 3 \\
\hline Maçaranduba & Manilkaraamazonica & 3 \\
\hline Cupiúba, & Goupia glabra & 3 \\
\hline Angá/Ingá & Inga vera & 3 \\
\hline Total & & 100 \\
\hline
\end{tabular}

FONTE: Pesquisa de campo.

TABELA 2 - Espécies que são eliminadas durante a prática de limpeza de área ou tratos culturais do açaizeiro, indicadas na pesquisa.

\begin{tabular}{|c|c|c|}
\hline Nome Vulgar & Nome Científico & Percentual (\%) \\
\hline Ucuuba & Virola surinamensis & 22 \\
\hline Cipó Preto & Hippocrateavolubilis & 11 \\
\hline Jupati & Raphiataedigera & 11 \\
\hline Seringueira & Hevea brasiliensis & 11 \\
\hline Aninga & Philodendronspeciosum & 11 \\
\hline Total & & 100 \\
\hline
\end{tabular}

FONTE: Pesquisa de campo. 
que concorrem com o açaizeiro por nutrientes e até mesmo por água (Tabela 2).

Embora o açaizeiro seja uma espécie nativa encontrada abundantemente nas áreas de várzea, o que se constata é um aumento expressivo do número de indivíduos dessa espécie e, principalmente, a eliminação de outras espécies importantes e comuns àquele ecossistema. Dentre estas espécies está a aninga (Montrichardia linifera), que tem papel preponderante na contenção de barrancos e que é capaz de absorver grandes quantidades de minerais presentes no solo e água, uma vez que funciona como filtro natural (Figura 7).

Segundo Amarante et al. (2009), a aninga desempenha um papel importante na retenção de sedimentos e na dieta de peixes, répteis e mamíferos, em especial os herbívoros como o peixe-boi, bem

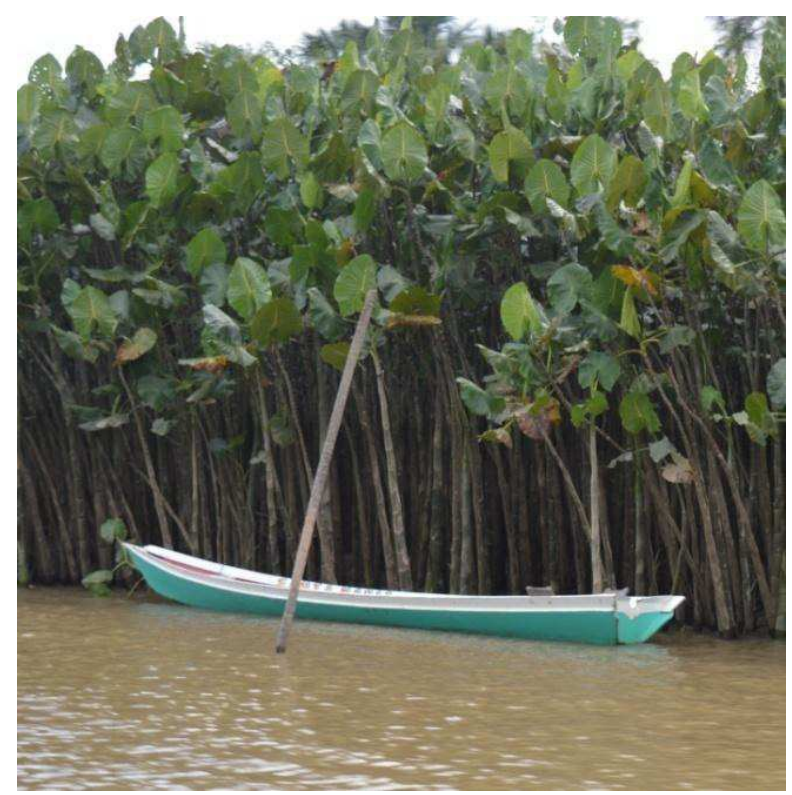

FIGURA 7 - Aninga à margem dos rios. FONTE: Pesquisa de campo. como servem de refúgio para desova e reprodução de peixes.

Teixeira et al. (2014) atribuem aos ribeirinhos a eliminação da aninga das margens dos rios. Segundo os autores, os ribeirinhos consideram a seiva da aninga venenosa e acreditam que ela causa queimaduras na pele, sobretudo porque servem de abrigo para animais peçonhentos. Durante a visita exploratória, os ribeirinhos entrevistados relataram que a diminuição dessa espécie se dá não só por conta do aumento das áreas para o desenvolvimento do açaizeiro, uma vez que a aninga é competitiva e de fácil regeneração após sua retirada, mas também porque a sua eliminação facilita a visualização e o acesso das áreas de terra firme para o rio.

A erosão das margens dos rios (Figura 8) também vem se agravando pelo aumento do fluxo

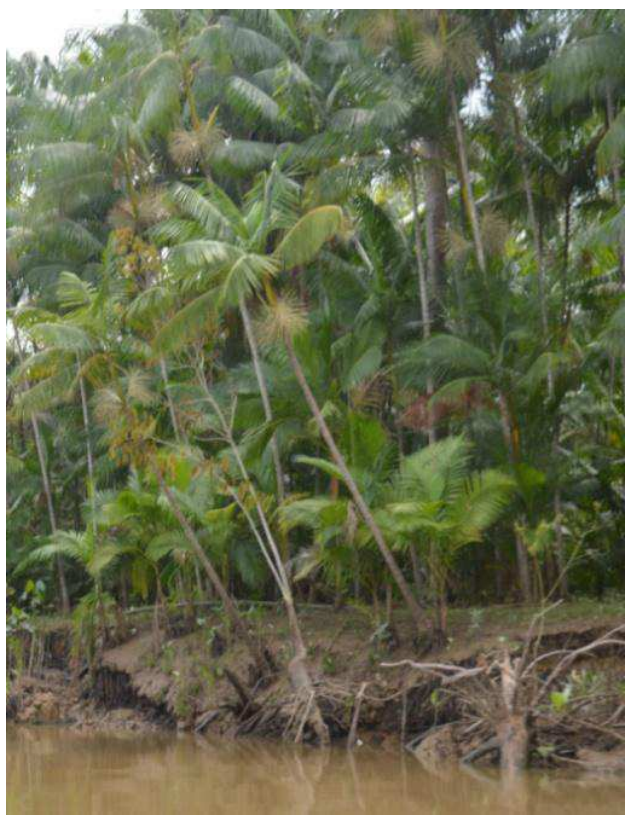

FIGURA 8 - Erosão à margem dos rios.

FONTE: Pesquisa de campo. 
de embarcações no curso de navegação. O fluxo de embarcações contribui para a remoção dos materiais do barranco, devido às ondas provocadas durante a passagem dos barcos. Consequentemente, há um aumento na largura dos canais e assoreamento a partir da sedimentação da terra dos barrancos, o que altera os cursos dos rios e o acesso aos mesmos. A erosão e o assoreamento dos rios foram apontados espontaneamente por $50 \%$ dos entrevistados como os principais problemas do ambiente natural da região. $\mathrm{Na}$ área produtiva dos ribeirinhos, constatamos, ainda, que ocorre uma mudança na espacialidade da área de coleta do fruto do açaí, demonstrando que as alterações estão para além dos aspectos do ambiente físico.

A exploração deixa de ser extensiva, resultando no processo de cercamento, ou seja, há delimitação dos espaços geográficos de coleta reservados a cada família. As famílias têm ampliado suas áreas de trabalho, o que tem demandado uma maior quantidade de pessoas para a atividade produtiva do açaí. Dessa forma, ocorre uma nova configuração da estrutura de produção familiar por conta da contratação de mão de obra de terceiros, desconfigurando a perspectiva do PRONAF enquanto sistema creditício para a agricultura familiar.

Ao considerarmos os riscos ambientais já instaurados, o padrão de exploração intensivo das áreas de várzea gera perda da diversidade desse ecossistema, o que resulta em: (1) homogeneização da paisagem por conta do monocultivo do açaí; (2) eliminação de espécies vegetais que, por sua vez, resulta na diminuição de outras espécies vegetais e animais; (3) aumento de espécies nocivas ao homem, o que pode resultar em doenças e pragas; e (4) erosão e assoreamento dos rios.
A ausência do debate a respeito das implicações resultantes das práticas do manejo intensivo dos açaizais diminui a capacidade de mitigar as alterações da configuração do ecossistema, o que envolve as dinâmicas naturais, econômicas e sociais.

\section{Considerações finais}

O manejo intensivo dos açaizais nas áreas de várzea tem proporcionado um aumento na produção e renda aos ribeirinhos. Entretanto, tem implicado em alterações na configuração do ambiente natural, incluindo a homogeneização da paisagem, o que coloca em risco a sustentabilidade do ecossistema de várzea como um todo.

As alterações decorrentes do manejo intensivo das áreas de várzea e os demais impactos advindos desse processo precisam ser acompanhados e analisados constantemente, sobretudo em áreas de proteção permanente (APP). Nas APP somente é permitida a realização de atividades de baixo impacto, de modo a preservar os recursos hídricos, a paisagem e a biodiversidade. Contudo, o que vem sendo observado nessas áreas não condiz com o que está preconizado pela lei, visto que as áreas de APP têm se configurado em plantios homogêneos de açaí, conforme foi evidenciado ao longo deste artigo.

A questão pautada é que a valorização econômica do açaí, estimulada e financiada por políticas públicas do Estado, tem levado à implantação de plantios e modelos de manejo que colocam em risco o equilíbrio ambiental onde se instalam. As alterações decorrentes dos processos de mudança na base tecnológica de produção do açaí, além das práticas adotadas nas áreas de várzea, modificam substancialmente a paisagem e o ecossistema. 
Cada uma das espécies desempenha um papel importante no ambiente natural, seja para a manutenção de outros organismos que dependem de sua existência na cadeia alimentar dos seres vivos, seja para proteção de beira de rios evitando o desbarrancamento. Por esses motivos, podemos concluir que os riscos da perda da biodiversidade, em se tratando de um ecossistema extremamente complexo e frágil, como é o caso das áreas de várzea, podem tomar proporções desastrosas e até mesmo irreversíveis em um curto espaço de tempo.

A oportunidade da valorização econômica do açaí deve ser aproveitada como elemento de reconhecimento da atividade extrativista. Contudo, essa questão deve ser pautada pelos princípios da sustentabilidade de sua cadeia produtiva, em outras palavras, a oportunidade da valorização econômica do açaí não pode colocar em risco o ecossistema do qual se origina.

Vislumbra-se a necessidade de implantação de políticas públicas que consigam frear esse processo e proponham alternativas para minimizar os impactos negativos e/ou estimular os positivos.

Quaisquer que sejam as soluções para minimizar esses riscos ambientais, essa tarefa deve envolver os diferentes segmentos da sociedade através de processos de cooperação, confiança e sinergia entre indivíduos e organizações, de modo a alcançar um objetivo comum com valorização de práticas de manejo que preservem o ecossistema da várzea.

\section{Referências}

Amarante, C. B. do; Silva, J. C. F. da; Solano, F. A. R.; Nascimento, L. D. do; Moraes, L. G.; Silva, F. G.; Uno, W. S. Estudo espectrométrico das folhas da Aninga (Montrichar- dia linifera) coletadas à margem do rio Guamá no campus da UFPA, Belém-PA: uma contribuição ao estudo químico da família Araceae. Revista Científica da UFPA, 7(1), 2009.

Banco Central. Resolução n ${ }^{\circ} 219$, de 24 de agosto de 1995, institui o Programa Nacional de Fortalecimento da Agricultura Familiar (PRONAF). 2016/2017.

Balogh, T. S. Uso cosmético de extratos glicólicos: avaliação da atividade antioxidante, estudo da estabilidade e potencial fotoprotetor. 2011. 267 f. Dissertação (Mestrado em Fármaco e medicamentos) - Faculdade de Ciências Farmacêuticas da Universidade de São Paulo. São Paulo, SP.

Beck, U. Sociedade de risco: rumo a uma outra modernidade. São Paulo: Ed. 34, 2010. 384p.

Benatti, L. P. Inovação nas técnicas de acabamento decorativo em sementes ornamentais brasileiras: design aplicado a produtos com perfil sustentável. 2013. 146 f. Dissertação (Mestrado em Design) - Programa de Pós-Graduação em Design, Universidade do Estado de Minas Gerais, Belo Horizonte, Minas Gerais.

Bianchini, V. Vinte anos do PRONAF, 1995 - 2015: avanços e desafios. Brasília, SAF/MDA, 2015.

Calzavara, B. B. G. Açaizeiro. Recomendações Básicas, 3. EMBRAPA-CPATU, Belém, PA, 1987.

Canto, O. do. Várzea e Varzeiro da Amazônia. Belém: MPEG, 2007. (coleção Eduardo Galvão)

Castro, E. M. R. de; Marques, G. de S.; Acioli. E. de J. F. Expansão da atividade madeireira no Pará, desmatamento e politica florestal. In: Menezes, C. R. C.; Monteiro, M. A.; Galvão, I. M. F. Zoneamento Ecológico-Econômico da Zona Leste e Calha Norte do Estado do Pará. NGPR, Belém, PA, 2010.

Cavalcante, P. Frutas comestiveis da Amazônia. Belém: CEJUP, 1991.271p.1991

CONAB - Companhia Nacional de Abastecimento. Produtos da sociobiodiversidade, safra 2015/2016 - Volume II. Brasília, DF, 2015.

Diegues, A. C. Os Saberes Tradicionais e a Biodiversidade no Brasil. São Paulo: NUPAUB/USP, PROBIO/ MMA, CNPq, 1999 
Herculano, F. E. B. Produção industrial de cosméticos: o protagonismo da biodiversidade vegetal da Amazônia. 2013. 143f. Tese (Doutourado em Biotecnologia) - Programa Multi-Institucional de Pós-Graduação em Biotecnologia (PPGBIOTEC), Universidade Federal do Amazonas UFAM, Manaus, Amazonas.

Homma, A. K. O. A extração de recursos naturais renováveis: o caso do extrativismo vegetal na Amazônia. 1989. 575 f. Tese (Doutorado em Economia Rural) - Departamento de Economia Rural, Universidade Federal de Viçosa, Viçosa, MG.

Homma, A. K. Extrativismo vegetal ou plantio: qual a opção para a Amazônia? In: Homma, A. K. O. (Ed.). Extrativismo vegetal na Amazônia: história, ecologia, economia e domesticação. Brasília, DF: Embrapa, 2014.

INCRA - Instituto Nacional de Colonização Agrícola. Mapa assentamentos rurais. 2016. Disponível em: $<$ http:// acervofundiario.incra.gov.br/i3geo/interface/incra.html?i2dr3h6pqv4ans097od4sbvus6>Acesso em 15 ago. 2016.

Jardim, M. A. G.; Anderson, A. B. Manejo de populações nativas de açaizeiro no estuário amazônico: resultados preliminares. Boletim de Pesquisa Florestal, 15, 1-18, 1987.

Jardim, M. A. G. Aspectos da biologia reprodutiva de uma população natural de açaizeiro (Euterpe oleracea Mart.) no Estuário Amazônico. 1991. 91p. Dissertação (Mestrado em Ciências Florestais) - Escola Superior de Agricultura Luiz de Queiroz, Piracicaba, 1991.

Junk, W. J. The Central Amazon Floodplain: Ecologyof a Pulsing System. Springer, New York.1997.

Junk, W. J.; Bayley, P. B.; Sparks, R. E. The flood pulse concept in river-floodplain systems.Canadian. Journal of Fishers and Aquatic, 106, 110-127, 1989.

Leite, J. R. M.; Ayala, P. A. Transdisciplinaridade e a Proteção Jurídico-ambiental em Sociedade de Risco: Direito, Ciência Participação In: Leite, J. R. M.; Bello Filho, N. B. (org.). Direito ambiental contemporâneo. Barueri, SP: Manole, 2004. p. 99-127.

Lopes, M. L. B.; Santana, A.C. O mercado do fruto do açaizeiro (Euterpe oleracea Mart.) no estado do Pará. In: Carvalho, D. F. (Org.). Economia da Amazônia nos anos 90.
Belém, Universidade da Amazônia. p.65-84.2005.

Menezes, M. N. A.; Guerra, G. A. D. Exploração de madeiras no Pará: semelhanças entre as fábricas reais do período colonial e as atuais serrarias. Cadernos de Ciência \& Tecnologia, 15(3), 125-145, 1998.

Monteiro, M. A. Habitus, governanças institucionais e trajetórias tecnológicas: uma análise sociológica do espaço, o caso da expansão do óleo de palma (dendê) no vale do Acará, Pará. 2017. 294f. Tese (Doutourado em Desenvolvimento Sustentável do Trópico Úmido) - Programa do Núcleo de Altos Estudos Amazônicos (NAEA) - Universidade Federal do Pará - UFPA, Belém, Pará.

Mourão, L. História e natureza: do açaí ao palmito. Revista Territórios e Fronteiras, 3(2), 2010.

Nogueira, O. L. Regeneração, manejo e exploração de açaizais nativos de várzea do estuário amazônico. $149 \mathrm{f}$. Tese (Doutorado em Ciências) - Universidade Federal do Pará, Museu Paraense Emílio Goeldi, Empresa Brasileira de Pesquisa Agropecuária, Belém, 1997.

Nogueira, O. L.; Calzavara, B. B. G.; Müller, C. H.; Moreira, D. A. Manejo de açaizeiros (Euterpe oleracea Mart.) cultivados em Latossolo Amarelo na Amazônia. Revista Brasileira de Fruticultura, 20(1), 53-59, 1998.

Nogueira, O. L.; Homma, A. K. O. Importância do manejo de recursos extrativos em aumentar a capacidade de suporte: o caso de açaizeiros (Euterpe oleracea Mart,) no estuário amazônico In: Homma, A. K. O. (Ed.). Extrativismo Vegetal na Amazônia: história, ecologia, economia e domesticação. Brasília, DF: Embrapa, 2014.

Ohashi, S. T.; Kageyama, P. Y. Variabilidade genética entre populações de açaizeiro (Euterpe oleracea Mart.) do estuário amazônico. In: Mourão, L.; Jardim, M. A.; Grossmann, M. (Eds.). Açaí: possibilidade e limites em processos de desenvolvimento sustentável no estuário amazônico. Belém: CEJUP, 2004. p.11-26

Oliveira, L. P. de. Programa de Desenvolvimento da Cadeia Produtiva do Açai no Estado do Pará-PROAÇAÍ. Belém: SEDAP, 2016.

Passos, L. A. C.; Guarald, A. M. A.; Barbosa, R. L.; Dias, V. L.; Pereira, K. S.; Schmidt, F. L.; Franco, R. M. B.; Alves, 
D. P. Sobrevivência e infectividade do Trypanosoma cruzi na polpa de açaí: estudo in vitro e in vivo. Epidemiologia Serviço de Saúde, 21(2), 2012.

Pires, J. M.; Prance, G. T. Notes on the vegetation types of the Brazilian Amazon. In: Prance, G. T.; Lovejoy, T. E. (Eds.). Key environments: Amazonia, pp. 109-145. Pergamon Press, Oxford. 1985.

Ragin, C. C. The comparative method: moving beyond qualitative and quantitative strategies. Berkeley: University of California Press, 1987.

Santana, A. C.; Carvalho, D. F.; Mendes, F. A. T. Organização e competitividade das empresas de polpas de frutas no Estado do Pará: 1995 a 2004. Belém, Unama, 2006.

Silva, P. J. D. da; Almeida, S. S. de. Estrutura ecológica de açaizais em ecossistemas inundáveis da Amazônia. In: Jardim, M. A. G.; Mourão, L.; Grossmann, M. (Ed.). Açaí: possibilidades e limites para o desenvolvimento sustentável no estuário amazônico. Belém: Museu Paraense Emílio Goeldi, 2004. p. $37-51$.
Sioli, H. Amazônia, Petrópolis, Vozes. 1985

Tagore, M. P. B. O aumento da demanda do açaí e as alterações sociais, ambientais e econômicas: o caso das várzeas de Abaetetuba, Pará. 2017. f 156. Dissertação (Mestrado em Gestão de Recursos Naturais e Desenvolvimento Local na Amazônia) - Universidade Federal do Pará, Belém, 2017.

Teixeira, D. F. F.; Siqueira, B. S.; Cattanio, J. H. Importância da Aninga (Montrichardia linifera) na retenção de sedimentos na baia do Guajará, PA. Revista de estudos ambientais (Online), 16(2), 6-19, 2014.

Vasconcellos Sobrinho, M.; Vasconcellos, A. M. A. Aprendendo com a prática: experiência de parceria entre universidade, governo, sociedade civil e mercado na análise territorial integrada e planejamento do desenvolvimento municipal. In: Rocha, G. M.; Vasconcellos Sobrinho, M. (Org.). Aprendizagem Territorial: dinâmicas territoriais, participação social e ação local. Belém, NUMA/UFPA, 2016. 